\title{
Meningioma and breast cancer: survival of patients with synchronous and metachronous meningioma and breast cancer
}

\author{
José Pedro Lavrador ${ }^{1,2,3}$ • Marta Valente Pinto ${ }^{1,4} \cdot$ Luís Mascarenhas Lemos $^{1,5}$ • \\ Catarina Ribeiro ${ }^{1,6,7} \cdot$ André Peralta Santos ${ }^{1}$
}

Received: 19 November 2016 / Accepted: 22 October 2017 / Published online: 8 November 2017

(C) Springer Science+Business Media, LLC 2017

\begin{abstract}
The prognosis of the association between Breast Cancer (BC) and Meningioma (M) is unknown. To evaluate the survival impact of tumor exposure sequence in patients with both tumors. Patients were divided in groups according to the tumors sequence: $\mathrm{BC}$ before $\mathrm{M}$ (group 1), synchronous $\mathrm{BC}+\mathrm{M}$ (group 2) and $\mathrm{BC}$ after $\mathrm{M}$ (group 3). The SEER database was used. Demographics, meningioma and breast cancer variables were analyzed. The primary outcome was oncological survival. A total of 1715 patients were included (median follow-up:84 months). Group 2 had the shortest survival (median:32 months) and group 1 the longest (median:110 months). On the unadjusted analysis, group 2 had the shortest survival (HR:3.13, 95\% CI 1.626.04) and adjusted analysis confirmed this finding (HR 3.11, 95\% CI 1.58-6.19), with no statistical difference between the metachronous tumors groups. Increasing age (HR:1.13,
\end{abstract}

José Pedro Lavrador

jose.pedro.lavrador@gmail.com

1 The Portugal Clinical Scholars Research Training Program, Lisbon, Portugal

2 Neurosurgical Department, Hospital Santa Maria, Centro Hospitalar Lisboa Norte, Lisbon, Portugal

3 Department of Paediatric and Adult Neurosurgery, King's College Hospital NHS Foundation Trust, Denmark Hill, London, UK

4 Oxford Vaccine Group, Department of Paediatrics, University of Oxford, Oxford, UK

5 Pathology Department, Centro Hospitalar Lisboa Central, Lisbon, Portugal

6 Department of Medical Oncology, Centro Hospitalar Lisboa Central, Lisbon, Portugal

7 Department of Palliative Care, Policy and Rehabilitation, Cicely Saunders Institute, King's College of London, London, UK
95\% CI 1.11-1.15, p < 0.005) and grade III meningioma (HR:4.51, 95\% CI 1.90-10.69, $\mathrm{p}<0.005$ ) were related with lower survival. Meningioma treatment had no influence on the survival $(\mathrm{p}>0.05)$. The association between surgery and radiotherapy in $\mathrm{BC}$ treatment improved the outcome (HR $0.37,95 \%$ CI $0.23-0.93, p<0.05$ ). Grade III meningioma and receptor hormonal status influenced synchronous tumors $(\mathrm{p}<0.05)$ but had no influence on metachronous tumors survival $(p>0.05)$ on stratified analysis. Synchronous tumors were associated with lower survival. Increasing age had a negative influence on patient survival. Although surgery and radiotherapy for breast cancer had a positive influence in the outcome, meningioma treatment was not related with survival. Grade III meningioma and hormonal receptor status only influenced synchronous tumors patient survival.

Keywords Meningioma - Breast cancer - Treatment . Survival $\cdot$ Epidemiology

\section{Introduction}

Meningiomas (M) are arachnoidal-cell derived tumors accounting for $20-30 \%$ of primary intracranial tumours [1, 2]. According to World Health Organization (WHO) classification, most Meningiomas are grade I, with grade II lesions comprising $420-30 \%$ and grade III lesions 1.0 to $2.8 \%$. They are more frequent in elderly patient (60-70 years) with a female predominance (3.5:1 female:male ratio).

Breast cancer (BC) is the most common malignancy in women. The incidence rate of breast cancer has been decreasing in the last decades (in 2011 about $130-135$ per $100,000)[1,2]$ and the survival has been increasing (84 and 89-92\% 5-year progression free survival (PFS) and overall survival (OS) respectively) [3, 4]. The hormonal influence 
of a higher number of breast cancer subtypes has an impact on treatment choices.

Schoenberg et al. in 1975 [5] described, for the first time, an increased incidence of meningiomas in the group of patients diagnosed with breast cancer. This association is still not clear since epidemiological studies and other reports show contradictory findings [5-11]. In 1979 Donnell et al. described the importance of estrogen receptors (ER) in meningiomas. Progesterone receptors (PR) were also identified in meningioma cells, becoming the main hormone receptor recognized in those cells (70\% PR versus 30\% ER [12]). PR negative meningiomas tend to be larger and are normally classified as grade II or grade III. The absence of PR's or ER's expression is related with a more aggressive behavior, higher risk of progression and higher recurrence [13]. PR's, grade and mitotic index are combined in a prognostic index related with patients' outcome where absence of PR's and higher grade and mitotic index are related with poorer prognosis $[11,12]$.

When considering cytogenetic and genetic analysis, absence of PR's or presence of ER's was related with karyotype abnormalities, namely in chromosomes 14 and 22. [14, 15] Genetic analysis has also supported the M-BC association as a variation in DNA-helicase BRIP1 (BRCA1 interacting protein C-terminal helicase 1) and ATM (ataxia-telangiectasia mutated) gene (phosphatidylinositol-3-kinase family related with DNA breakdowns repair) has been related with both meningioma and low-risk variants of breast cancer [16, 17]. Despite the relevance in some breast cancers, [BRCA (Breast Cancer) 1 and 2] mutations are not common in meningiomas [14]. Therefore the clinical impact of these findings has not been proven and no widely used prognostic score using genetic testing has been established.

Although a clinical association between meningioma and breast cancer has been described as well-women with both lesions have smaller-sized meningiomas and more advanced BC-[18], findings considering the impact of this association in patients' survival are scarce. Therefore, our aim was to evaluate the survival impact of tumor exposure sequence-synchronous or metachronous - in patients with both tumors.

\section{Materials and methods}

\section{Study population}

The SEER database-SEER 18 (November 2014), 1973-2012 — of the National Institute of cancer in the United States of America was used to conduct a retrospective cohort study. This collects information on Cancer incidence and survival in the United States covering around $28 \%$ of the population. [4, 19].
Adult patients with meningioma and associated breast cancer were identified. All patients diagnosed with other tumors apart from the ones specified above were excluded.

No IRB/ethics committee approval or patient consent was needed to conduct this study as per SEER Dataset requirements. $[4,19]$.

\section{Exposure}

Three groups were defined: group 1 - patients with meningioma diagnosed after the breast cancer diagnosis $(\mathrm{BC} \rightarrow$ $\mathrm{M}$ ), group 2-patients with synchronous meningioma and breast cancer $(\mathrm{M}+\mathrm{BC})$ and group 3-patients where meningioma preceded the diagnosis of breast cancer $(\mathrm{M} \rightarrow \mathrm{BC})$. Group 3 was considered the reference group. The definition of synchronous meningioma and breast cancer was defined as those tumours diagnosed in the same year.

\section{Outcome}

The outcome was death attributed to one of the cancers in the study (meningioma or breast cancer). The survival was measured in months after the diagnosis of the first tumor.

\section{Covariables}

Demographic and clinical characteristics such as: age at diagnosis, gender, race/ethnicity, meningioma site, grade and associated treatment, breast cancer grade and treatment and breast cancer receptors (estrogen and progesterone) were analysed $[4,19]$.

\section{Statistical analysis}

Chi square test was used to compare frequency distributions of variables between patient subgroups and analysis of variance was used to compare the means of continuous variables.

The individuals with missing values in the survival time were excluded from the survival analysis. To explore the survival graphically we computed a Kaplan-Meier graph. In addition, we used the Cox proportional hazards models to compute hazard ratios (HR) and the $95 \%$ confidence intervals (CI) of the mortality risk. The proportionality of hazards assumption was evaluated visually and graphically using the Schoenfeld residuals. P values $<0.05$ were considered significant. We constructed two models, one unadjusted and the final model adjusted for the co-variables above mentioned. We tested interactions between the co-variables and the sequence of breast cancer and meningioma. The covariables with positive interactions were stratified. Because of its importance as a possible effect modifier we tested an age interaction in the linear, quadratic, and cubic scale. The 
SEER*Stat Case Listing Session was used to retrieve all the participants that fulfilled the inclusion criteria. For the statistical analysis we used STATA 13.

\section{Results}

\section{Population characteristics}

Using the SEER database, 1796 patients (99,8\% women) with both meningioma and breast cancer were analyzed, 82 (4.6\%) were excluded from the survival analysis due to missing data regarding the follow-up. Group $1(\mathrm{BC} \rightarrow \mathrm{M})$ was the group with a higher number of patients $(64.5 \%)$ followed by group $3(\mathrm{M} \rightarrow \mathrm{BC})-20.9 \%$-and group $2(\mathrm{M}+\mathrm{BC})-$ $14.6 \%$. The mean age at diagnosis (considering the first tumour diagnosis) was higher in group 2 (65.9 (13.2) years, $\mathrm{p}<0.001)$. White patients presented with a higher number of cases in all three groups. The mean time from the first tumor to the second was 7.6 years in group $1(\mathrm{BC} \rightarrow \mathrm{M})$ and 2.9 years in group 3 [data not shown in tables].

The clinic and pathologic features analyzed for meningioma were the site, grade and treatment. In all groups the most common location was the cerebral meningioma (group 1(BC $\rightarrow \mathrm{M}$ ): 84.9\%; group $2(\mathrm{M}+\mathrm{BC}$ ): 86.6\%; group $3(\mathrm{M} \rightarrow \mathrm{BC}): 85.9 \%)$ and in all groups the non-treatment approach was the most common (group $1(\mathrm{BC} \rightarrow \mathrm{M}): 59 \%$; group 2(BC+M): $74,4 \%$; group $3(\mathrm{M} \rightarrow \mathrm{BC}): 46.8 \%)$. The majority of patients submitted to surgery were in group 3 $(\mathrm{M} \rightarrow \mathrm{BC})-44.4 \%$ versus $33.2 \%$ in group $1(\mathrm{BC} \rightarrow \mathrm{M})$ and $21.4 \%$ in group $2(\mathrm{BC}+\mathrm{M})$. Group $2(\mathrm{M}+\mathrm{BC})$ was the one with less patients submitted to radiotherapy $[4.2 \%$ versus $7.8 \%$ in group $1(\mathrm{BC} \rightarrow \mathrm{M})$ and $8.8 \%$ in group $3(\mathrm{M} \rightarrow \mathrm{BC})]$ ( $\mathrm{p}$ value $<0.001$ ). In the majority of the cases, the grade of the meningioma was not specified (as no surgical resection or biopsy were addressed and therefore no specimen was obtained).

Regarding breast cancer clinicopathologic characteristics, in all groups, the most common grade of breast cancer was "moderately differentiated" (group $1(\mathrm{BC} \rightarrow \mathrm{M}): 35.4 \%$; group $2(\mathrm{BC}+\mathrm{M}): 38.2 \%$; group $3(\mathrm{M} \rightarrow \mathrm{BC}): 39.9 \%)$ followed by "poorly differentiated" (group $1(\mathrm{BC} \rightarrow \mathrm{M}): 27.2 \%$, group 2(BC+M): $34.4 \%$; group $3(\mathrm{M} \rightarrow \mathrm{BC}): 30.6 \%)$. Considering breast cancer stage, group $2(\mathrm{BC}+\mathrm{M})$ had the higher prevalence of "regional" $[36.3 \%$ versus $25.6 \%$ in group $1(\mathrm{BC} \rightarrow \mathrm{M})$ and $27.1 \%$ in group $3(\mathrm{M} \rightarrow \mathrm{BC})]$ and "distant" (19.8 versus $3.1 \%$ in group 1 and $4.0 \%$ in group $3)$ tumors. On the other hand, group $1(\mathrm{BC} \rightarrow \mathrm{M})$ had the higher prevalence of "in situ and localized" tumors (71.2\% versus $68.9 \%$ in group $3(\mathrm{M} \rightarrow \mathrm{BC})$ and $43.9 \%$ in group 2 $(\mathrm{BC}+\mathrm{M})$ : $(\mathrm{p}$ value $<0.001)]$. "Surgery and radiotherapy" was the main treatment option in all groups (group $1(\mathrm{BC} \rightarrow$ $\mathrm{M})-49.9 \%$, group $2(\mathrm{BC}+\mathrm{M})-45.0 \%$ and group $3(\mathrm{M} \rightarrow$
BC)-64.5\%) while "surgery" alone was more prevalent in group $1(\mathrm{BC} \rightarrow \mathrm{M})$ [49.8 versus $38.2 \%$ in group $2(\mathrm{BC}+\mathrm{M})$ and $15.7 \%$ in group $3(\mathrm{M} \rightarrow \mathrm{BC})]$ and "no treatment" had a higher prevalence in group $2(\mathrm{BC}+\mathrm{M})[14.5$ versus $3.0 \%$ in group $1(\mathrm{BC} \rightarrow \mathrm{M})$ and $8.4 \%$ in group $3(\mathrm{M} \rightarrow \mathrm{BC})](\mathrm{p}$ value $<0.001)$. Concerning breast cancer hormonal receptor status, both receptors were positive in $64.4 \%$ of group 3(M $\rightarrow \mathrm{BC}), 59.2 \%$ of group $2(\mathrm{BC}+\mathrm{M})$ and $46.7 \%$ in group 1 $(\mathrm{BC} \rightarrow \mathrm{M})$ patients $(\mathrm{p}$ value $<0.001)$ (Table 1$)$.

\section{Survival analysis}

The study population of 1715 participants was followed for 176.437 person/month, with a total of 172 deaths. Group $1(\mathrm{BC} \rightarrow \mathrm{M})$ had the largest number of deaths-136 (death attributed to breast cancer or meningioma). Both groups 2 $(\mathrm{BC}+\mathrm{M})$ and $3(\mathrm{M} \rightarrow \mathrm{BC})$ had 18 deaths each; 154 deaths were attributed to breast cancer and 18 to meningioma. The median overall survival in months after the diagnosis of the first tumor was lower in group $2(\mathrm{BC}+\mathrm{M})$, with 32 months, and higher in group $3(\mathrm{M} \rightarrow \mathrm{BC})$, with 66 months, and group $1(\mathrm{BC} \rightarrow \mathrm{M}) 110$ months (Logrank Test $\mathrm{p}<0.001)$.

The unadjusted survival analysis showed that between group $1(\mathrm{BC} \rightarrow \mathrm{M})$ and group $3(\mathrm{M} \rightarrow \mathrm{BC})$, there was no statistical difference in the hazard risk of death (group 3 (M $\rightarrow$ BC) HR 0.87; 95\% CI 0.52-1.46, p:0.56), opposite to what was identified in group $2(\mathrm{BC}+\mathrm{M})(\mathrm{HR} 3.13,95 \% \mathrm{CI}$ $1.62-6.04, \mathrm{p}<0.001$ ) (Table 2).

The characteristics described in the literature particularly associated with meningioma that showed to have influence in the increase of risk of death in the adjusted analysis were: age at diagnosis of the first tumor (HR 1.13, 95\% CI $1.11-1.15, \mathrm{p}<0.005)$ and meningioma grade III (HR 4.51, 95\% CI 1.90-10.69, $\mathrm{p}<0.005$ ).

When considering the hormonal receptor status in the breast cancer specimens, the presence of both estrogen and progesterone receptors influence survival increasing the risk of death (HR 1.73, 95\% CI 1.18-2.85, p <0.05), when compared with "both receptors negative" (reference group) and "one receptor positive" (HR 1.46, 95\% CI 0.87-2.44, $\mathrm{p}>0.05$ ) (Table 3).

When stratifying for meningioma grade, in the first group of grade I, II and unknown (grouped together due to the insufficient number of deaths to analyze the categories separately) only the synchronous cancers posed a risk for mortality (HR 3.13, 95\% CI 1.62-6.04, p <0.001). In the grade III meningioma, only the synchronous cancers posed a risk for mortality but with a very high HR (HR 80.6, 95\% CI 5.25-1236.9, $\mathrm{p}<0.001$ ) (Table 4).

When stratifying for breast cancer hormonal receptor status, only the synchronous cancers have a significant HR. An increased risk of death is noted in $\mathrm{BC}+\mathrm{M}$ group when at least one of the tested hormonal receptor is 
Table 1 Baseline characteristics of the patients with meningioma and meningioma and breast cancer at any time

\begin{tabular}{|c|c|c|c|c|c|}
\hline & \multicolumn{4}{|c|}{ Meningioma and breast cancer at any time } & \multirow[t]{2}{*}{ Overall } \\
\hline & $\begin{array}{l}\mathrm{BC} \rightarrow \text { Meningioma } \\
N(\%)\end{array}$ & $\begin{array}{l}\mathrm{BC}+\text { Meningioma } \\
N(\%)\end{array}$ & $\begin{array}{l}\text { Meningioma } \rightarrow \text { BC } \\
N(\%)\end{array}$ & $\mathrm{p}$ value & \\
\hline Total n (\%) & $1158(64.5)$ & $262(14.6)$ & $376(20.9)$ & & 1796 \\
\hline Age at the diagnosis (years) & $62.1(12.4)$ & $65.9(13.2)$ & $64.2(12.6)$ & $<0.001$ & 67.98 \\
\hline \multicolumn{6}{|l|}{ Sex } \\
\hline Female $(\%)$ & $1154(99.7)$ & $262(100)$ & $376(100)$ & $>0.05$ & 1792 \\
\hline \multicolumn{6}{|l|}{ Race } \\
\hline White & $967(83.5)$ & $213(81.3)$ & $306(81.4)$ & $>0.05$ & 1486 \\
\hline Black & $96(8.3)$ & $30(11.4)$ & $43(11.4)$ & & 169 \\
\hline Other & $95(8.2)$ & $18(6.9)$ & $27(7.2)$ & & 140 \\
\hline Unknown & 0 & $1(0.4)$ & 0 & & 1 \\
\hline \multicolumn{6}{|l|}{ Site of the meningioma } \\
\hline Cerebral meningioma & $984(85.0)$ & $227(86.6)$ & $323(85.9)$ & $>0.05$ & 1534 \\
\hline Spinal meningioma & $49(4.2)$ & $11(4.2)$ & $20(5.3)$ & & 80 \\
\hline Meningioma NOS & $125(10.8)$ & $24(9.2)$ & $33(8.8)$ & & 182 \\
\hline \multicolumn{6}{|l|}{ Grade meningioma } \\
\hline I & $133(11.5)$ & $27(10.3)$ & $60(16.0)$ & $>0.05$ & 220 \\
\hline II & $35(3.0)$ & $4(1.5)$ & $8(2.1)$ & & 47 \\
\hline III & $27(2.3)$ & $3(1.2)$ & $12(3.2)$ & & 42 \\
\hline Unknown & $963(83.2)$ & $228(87)$ & $296(78.7)$ & & 1487 \\
\hline \multicolumn{6}{|l|}{ Meningioma treatment } \\
\hline Surgery & $385(33.2)$ & $56(21.4)$ & $167(44.4)$ & $<0.001$ & 608 \\
\hline Radiotherapy & $90(7.8)$ & $11(4.2)$ & $33(8.8)$ & & 134 \\
\hline None & $683(59.0)$ & $195(74.4)$ & $176(46.8)$ & & 1054 \\
\hline \multicolumn{6}{|l|}{ Breast cancer grade } \\
\hline Well differentiated & $178(15.4)$ & $44(16.8)$ & $78(20.8)$ & $<0.001$ & 300 \\
\hline Moderately differentiated & $413(35.7)$ & $100(38.2)$ & $150(39.9)$ & & 663 \\
\hline Poorly differentiated & $318(27.5)$ & $90(34.4)$ & $115(30.6)$ & & 523 \\
\hline Undifferentiated & $31(2.7)$ & $4(1.5)$ & $5(1.3)$ & & 40 \\
\hline Unknown & $218(18.7)$ & $24(9.1)$ & $28(7.4)$ & & 270 \\
\hline \multicolumn{6}{|l|}{ Breast cancer stage } \\
\hline In situ and localized & $825(71.2)$ & $115(43.9)$ & $259(68.9)$ & $<0.001$ & 1199 \\
\hline Regional & $297(25.6)$ & $95(36.3)$ & $102(27.1)$ & & 494 \\
\hline Distant & $36(3.1)$ & $52(19.8)$ & $15(4.0)$ & & 103 \\
\hline \multicolumn{6}{|l|}{ Breast cancer treatment } \\
\hline Surgery & $577(49.8)$ & $100(38.2)$ & $182(15.7)$ & $<0.001$ & 859 \\
\hline Radiotherapy & $8(0.7)$ & $6(2.3)$ & $3(1.1)$ & & 17 \\
\hline Surgery and radiotherapy & $538(49.9)$ & $118(45.0)$ & $169(64.5)$ & & 825 \\
\hline No treatment & $35(3.0)$ & $38(14.5)$ & $22(8.4)$ & & 95 \\
\hline \multicolumn{6}{|c|}{ Breast cancer receptors (ER and PR) } \\
\hline Both negative & $449(38.8)$ & $63(24.0)$ & $86(22.8)$ & $<0.001$ & 598 \\
\hline One receptor positive & $168(14.5)$ & $44(16.8)$ & $48(12.8)$ & & 260 \\
\hline Both positive & $541(46.7)$ & $155(59.2)$ & $242(64.4)$ & & 938 \\
\hline
\end{tabular}

$N O S$ no other specification, $E R$ estrogen receptor, $P R$ progesterone receptor

$\mathrm{BC} \rightarrow$ Meningioma-Meningioma was diagnosed after the Breast cancer diagnosis, BC + Meningioma-meningioma and breast cancer are synchronous cancers, Meningioma $\rightarrow \mathrm{BC}-$ Meningioma preceeds the diagnosis of breast cancer 
Table 2 Hazard ratios for death of breast cancer and/ or meningioma-unadjusted analysis

Table 3 Hazard ratios for death of breast cancer and/or meningioma-Adjusted analysis

\begin{tabular}{|c|c|c|c|c|}
\hline & No of subjects & Hazard ratio & $\mathrm{p}$ value & $(95 \% \mathrm{CI})$ \\
\hline Variable & 1715 & & & \\
\hline \multicolumn{5}{|c|}{ Death by meningioma and breast cancer } \\
\hline \multicolumn{5}{|l|}{ Unadjusted } \\
\hline Meningioma $\rightarrow$ BC & & 1 (Ref.) & & \\
\hline $\mathrm{BC}+$ Meningioma & & 3.13 & 0.001 & $(1.62-6.04)$ \\
\hline $\mathrm{BC} \rightarrow$ Meningioma & & 0.87 & 0.56 & $(0.52-1.46)$ \\
\hline
\end{tabular}

$\mathrm{BC} \rightarrow$ Meningioma-Meningioma was diagnosed after the Breast cancer diagnosis, $\mathrm{BC}+$ MeningiomaMeningioma and breast cancer are synchronous cancers, Meningioma $\rightarrow \mathrm{BC}-$ Meningioma preceeds the diagnosis of breast cancer

\begin{tabular}{|c|c|c|c|c|}
\hline & No of subjects & Hazard ratio & $\mathrm{p}$ value & $(95 \% \mathrm{CI})$ \\
\hline Variable & 1715 & & & \\
\hline \multicolumn{5}{|c|}{ Death by meningioma or breast cancer } \\
\hline Meningioma $\rightarrow \mathrm{BC}$ & & 1 (Ref.) & & \\
\hline $\mathrm{BC}+$ Meningioma & & 3.13 & 0.001 & $(1.58-6.19)$ \\
\hline $\mathrm{BC} \rightarrow$ Meningioma & & 1.01 & $>0.05$ & $(0.65-1.90)$ \\
\hline Age at diagnosis (year) & & 1.13 & $<0.001$ & $(1.11-1.15)$ \\
\hline \multicolumn{5}{|l|}{ Grade of meningioma } \\
\hline I & & 1 (Ref.) & & \\
\hline II & & 1.48 & $>0.05$ & $(0.41-5.35)$ \\
\hline III & & 4.51 & 0.001 & $(1.90-10.69)$ \\
\hline Unknown & & 1.12 & $>0.05$ & $(0.55-2.26)$ \\
\hline \multicolumn{5}{|l|}{ Treatment of meningioma } \\
\hline None & & 1 (Ref.) & & \\
\hline Surgery & & 0.99 & $>0.05$ & $(0.62-1.56)$ \\
\hline Radiotherapy & & 0.90 & $>0.05$ & $(0.43-1.87)$ \\
\hline \multicolumn{5}{|l|}{ Breast cancer stage } \\
\hline In situ and localized & & 1 (Ref.) & & \\
\hline Regional & & 1.14 & $>0.05$ & $(0.81-1.62)$ \\
\hline Distant & & 0.27 & $>0.05$ & $(0.04-1.98)$ \\
\hline \multicolumn{5}{|l|}{ Treatment of breast cancer } \\
\hline No treatment & & 1 (Ref.) & & \\
\hline Surgery or radiotherapy & & 0.57 & $>0.05$ & $(0.29-1.14)$ \\
\hline Surgery and radiotherapy & & 0.37 & $<0.05$ & $(0.23-0.93)$ \\
\hline \multicolumn{5}{|c|}{ Breast cancer receptors (ER and PR) } \\
\hline Both negative & & 1 (Ref.) & & \\
\hline One receptor positive & & 1.46 & $>0.05$ & $(0.87-2.44)$ \\
\hline Both positive & & 1.73 & $<0.05$ & $(1.18-2.85)$ \\
\hline
\end{tabular}

$\mathrm{BC} \rightarrow$ Meningioma-Meningioma was diagnosed after the Breast cancer diagnosis, $\mathrm{BC}+$ MeningiomaMeningioma and breast cancer are synchronous cancers, Meningioma $\rightarrow \mathrm{BC}-$ Meningioma preceeds the diagnosis of breast cancer
positive-ER+/PR- or ER-/PR + or ER+/PR+ (both receptors negative: HR 4.10, 95\% CI 1.62-6.04, $\mathrm{p}<0.001$ and at least one receptor positive: HR 80.6, 95\% CI 5.25-1236.9, $\mathrm{p}<0.001$ ) (Table 5).

\section{Discussion}

The previous literature has focused on epidemiological relation and biological risk factors between breast cancer and 
Table 4 Hazard ratios for death of breast cancer and/or meningioma, stratified by grade meningioma (unadjusted)

\begin{tabular}{|c|c|c|c|c|}
\hline & No of subjects & Hazard ratio & $\mathrm{p}$ value & $(95 \% \mathrm{CI})$ \\
\hline Variable & 1715 & & & \\
\hline \multicolumn{5}{|c|}{ Death by breast cancer and meningioma } \\
\hline \multicolumn{5}{|c|}{ Meningioma grade I, II and unknown } \\
\hline Meningioma $\rightarrow$ BC & & 1 (Ref.) & & \\
\hline $\mathrm{BC}+$ Meningioma & & 3.13 & 0.001 & $(1.62-6.04)$ \\
\hline $\mathrm{BC} \rightarrow$ Meningioma & & 0.87 & 0.56 & $(0.52-1.46)$ \\
\hline \multicolumn{5}{|l|}{ Meningioma grade III } \\
\hline Meningioma $\rightarrow \mathrm{BC}$ & & 1 (Ref.) & & \\
\hline $\mathrm{BC}+$ Meningioma & & 80.6 & 0.001 & $(5.25-1236.9)$ \\
\hline $\mathrm{BC} \rightarrow$ Meningioma & & 2.61 & $>0.05$ & $(0.52-12.95)$ \\
\hline
\end{tabular}

$\mathrm{BC} \rightarrow$ Meningioma-Meningioma was diagnosed after the Breast cancer diagnosis, $\mathrm{BC}+$ MeningiomaMeningioma and breast cancer are synchronous cancers, Meningioma $\rightarrow \mathrm{BC}-$ Meningioma preceeds the diagnosis of breast cancer

\begin{tabular}{|c|c|c|c|c|}
\hline & No of subjects & Hazard ratio & $\mathrm{p}$ value & $(95 \% \mathrm{CI})$ \\
\hline Variable & 1715 & & & \\
\hline \multicolumn{5}{|c|}{ Death by breast cancer and meningioma } \\
\hline \multicolumn{5}{|c|}{ ER and PR receptors negative } \\
\hline Meningioma $\rightarrow$ BC & & 1 (Ref.) & & \\
\hline $\mathrm{BC}+$ Meningioma & & 4.10 & 0.001 & $(1.62-6.04)$ \\
\hline $\mathrm{BC} \rightarrow$ Meningioma & & 0.55 & 0.56 & $(0.52-1.46)$ \\
\hline \multicolumn{5}{|c|}{ ER or PR receptors positive } \\
\hline Meningioma $\rightarrow \mathrm{BC}$ & & 1 (Ref.) & & \\
\hline $\mathrm{BC}+$ Meningioma & & 80.6 & 0.001 & $(5.25-1236.9)$ \\
\hline $\mathrm{BC} \rightarrow$ Meningioma & & 2.61 & $>0.05$ & $(0.52-12.95)$ \\
\hline \multicolumn{5}{|c|}{ ER and PR receptors positive } \\
\hline Meningioma $\rightarrow \mathrm{BC}$ & & 1 (Ref.) & & \\
\hline $\mathrm{BC}+$ Meningioma & & 80.6 & 0.001 & $(5.25-1236.9)$ \\
\hline $\mathrm{BC} \rightarrow$ Meningioma & & 2.61 & $>0.05$ & $(0.52-12.95)$ \\
\hline
\end{tabular}

Table 5 Hazard ratios for death of breast cancer and/or meningioma, stratified by breast cancer receptor (unadjusted) such as gender, age, hormone exposure (endogenous or exogenous), and some epidemiological variants [10]. The majority of these studies are based on national oncological databases and share the limitation of controlling for confounding [20]. Therefore, an adjusted analysis for survival was performed considering age at diagnosis, meningioma grade, breast cancer receptors, treatment of meningioma and treatment of breast cancer.

Increased age at diagnosis (HR 1.13, 95\% CI 1.11-1.15) was related with worst prognosis (Table 3). Among elderly, most breast cancers are hormone-responsive [21] and meningiomas are benign in this gender. However, the decreased tolerance to treatment side effects and overall physiologic reserve often result in under treatment and higher mortality in this subgroup of patients [20]. 
Grade III meningioma was a risk factor for lower survival (HR 4.51, 95\% CI [1.90-10.69) (Table 4). In the literature, high recurrence and mortality rates (75 and $90 \%$ respectively in 5 years) are reported [22], which support the present results.

The biology of breast cancer cells was evaluated in terms of $\mathrm{ER}$ and $\mathrm{PR}$ receptors status. $\mathrm{ER}+/ \mathrm{PR}+$ receptor status was related with a worse outcome (HR 1.73, 95\%CI 1.18-2.85, $\mathrm{p}<0.05$ ) (Table 3). This was an unexpected result as the literature supports a better outcome in patients with ER positive breast cancer tumors and also because PR positive tumors are responsive to anti-hormonal treatment [23]. But the lack of information on the HER-2 receptors and details on the breast cancer stage does not allow any conclusions in this regard.

The treatment approach of meningiomas had no impact in overall survival ( $\mathrm{p}>0.05)$. On the other hand, when considering breast cancer treatment ("no treatment" as reference group), "surgery and radiotherapy" was related to a better survival (HR 0.37, 95\% CI 0.23-0.93) but "surgery or radiotherapy" alone did not influence the outcome (HR $0.57,95 \%$ CI 0.29-1.14) although no information concerning chemotherapy is available in this database. These results highlight a better outcome for a more aggressive oncological approach in breast cancer patients. These findings support the breast cancer treatment as one of the main prognostic factors in these patients, which was expected considering the overall higher aggressiveness of this tumor.

The adjusted analysis confirmed the previous results of unadjusted analysis for worst outcome of $\mathrm{BC}+\mathrm{M}$ group (HR $4.10,95 \%$ CI 1.62-6.04). (Table 3) One possible explanation for this finding is the expected morbility and mortality related with both tumors treatment and prognosis. This may reduce life expectancy in this group, as its effects are present for both tumors from the beginning of the exposure. On the other hand, in $\mathrm{BC} \rightarrow \mathrm{M}$ group the mean time between the tumors is 7.6 years where patient had been exposed to only one tumor and its effects. Nevertheless, only 18 death events where related with meningioma in the whole studied population, 2 in BC + M Group. Therefore, we can consider that the mortality due to meningioma was not responsible for this difference and hypothesize about a possible biological difference between both $\mathrm{BC}+\mathrm{M}$ and $\mathrm{BC} \rightarrow \mathrm{M}$ groups. Indeed, $\mathrm{BC}+\mathrm{M}$ had the higher prevalence of "poorly differentiated" (34.4\%) breast cancer grade, "regional" (36.3\%) and "distant" (19.8\%) breast cancer stage and"no treatment" approach either in meningioma (74.4\%) and in breast cancer $(14.5 \%)$. Unfortunately, in a significant amount of cases (1487 of meningiomas and 270 of breast cancer tumors out of 1796) the tumor grade is unknown, which does not allow further conclusions (Table 1). These results may support the fact that BC characteristics are different among these groups with a trend toward a greater aggressiveness in synchronous tumors. In fact, a possible interaction between both tumors is supported by the fact that both meningioma and breast cancer are able to produce peptides released in circulation with known promoter oncogenic role [24].

In this study, we looked for the influence in oncological survival of the biology and histology of meningioma and breast cancer in each group. The stratification of the study sample according to meningioma grade revealed no influence in $\mathrm{BC} \rightarrow \mathrm{M}$ group but only in $\mathrm{BC}+\mathrm{M}$ group. (Table 4) On the other hand, when we considered the stratification according to hormonal receptor status, a negative influence in the outcome was observed in the $\mathrm{BC}+\mathrm{M}$ group with no influence in the $\mathrm{BC} \rightarrow \mathrm{M}$ group (Table 5). These findings may provide an indirect support of an increased interaction and aggressiveness of synchronous tumors, as the oncological survival is dependent of meningioma grade- even though the missing data raises concerns about the power of this covariate analysis and the true impact of the meningioma grade in survival-and breast cancer biology, which does not happen in metachronous tumors. Nevertheless, hormonal receptor positivity is usually related with longer survival rates [25]. For unknown reasons, this was a paradoxal effect in this study.

Our results support for the first time the sequence of exposure as an important factor of prognosis in patients with both tumors. Even though dual-cancer patients outside of known syndromic or familial clinical situations are quite uncommon, a coherent statistical analysis was performed according to the dimension of study population.

Nevertheless, some limitations are noted. The used definition of synchronous tumors as tumors diagnosed in the same year may be questioned. However, this was the possible approach according to the provided year of diagnosis in the database. It should also be noted that the higher frequency of imaging exams performed during breast cancer staging procedures, may also be responsible for a higher number of diagnoses of synchronous tumors. However, this effect exists in all the 3 subgroups, as the follow-up for both malignances implies increased number of imaging exams. The diagnostic definition of meningiomas can also be questioned as 1188 cases have no histology to document (1054 of cases has no treatment and 134 had only radiotherapy) and the similar rate of grade II and III meningiomas doesn't find its parallel in the remaining literature which may highlight different diagnostic criteria along the recruitment time (1973-2012) and the need of a central review of the histological diagnosis. Nevertheless, magnetic resonance imaging has accurate methods to provide a proper diagnosis of meningioma in the majority of the cases (sensivity $83.3 \%$, specificity $100 \%$ and accuracy 93.3\%) [25]. Considering the majority of cases were collected in the last years (despite the database started in 1973), the diagnostic assumptions are valid for this study purposes. Finally, a concern towards residual confounding 
in this retrospective study exists as the adjustment for all the risk factors mentioned in the literature was not feasible. In this sense, we would like to point that no reliable information was found in database concerning chemotherapy. Indeed, this is not a major issue for meningiomas as the use of chemotherapy is residual. Nevertheless, it is one of the mainstays of therapy for disseminated breast cancer that should be considered in future studies.

Despite these limitations, this study provides an adjusted survival analysis for consensual risk factors in patients with both breast cancer and meningioma. In future studies, treatment-related morbidity should be considered and hormonal receptors should be evaluated not only for breast cancer but also for meningioma. New treatment approaches should be tested for different tumor exposure sequences, as this study suggests this as an important factor for oncological survival.

\section{Conclusion}

In this study, synchronous breast cancer and meningioma had shorter survival when compared with metachronous tumors, either in unadjusted or adjusted analysis. Increasing age and grade III meningioma were related with lower survival rates. Concerning the treatment approach to breast cancer, both surgery and radiotherapy were related to a better survival, whereas in meningioma treatment no particular approach proved to be superior when compared with the others. Meningioma grade and hormonal receptor status influenced only synchronous tumors (grade III and hormonal receptor positivity related with lower survival rates). A better understanding of this group of patients can provide valuable information for clinicians in order to provide a tailored clinical approach.

Acknowledgements The authors would like to thank to Clinical Scholars Research Training Harvard Medical Scholl Portugal Faculty for all the support given to the research included in this paper. They would also like to thank to Michel Milano, MD PhD, Ines Lains MD and Carla Bartosh MD for the help in sharing the methods used in their research which help the authors of this paper in designing this study.

Funding The authors had no funding to do the current study.

\section{Compliance with ethical standards}

Conflict of interest The authors have no conflict of interest to declare.

\section{References}

1. Backer-Grøndahl T, Moen BH, Torp SH (2012) The histopathological spectrum of human meningiomas. Int J Clin Exp Pathol 5(3):231-242
2. Chen HL, Ding A, Wang FW (2015) Prognostic effect analysis of molecular subtype on young breast cancer patients. Chin J Cancer Res 27(4):428

3. National Cancer Institute, Surveillance, Epidemiology and end results (SEER): SEER limite-use data 1973 - 201 (9 registries databases) [Internet]. [cited 2015 Oct 10];Available from http:// seer.cancer.gov

4. Shoenberg BS, Christine BW, Whisnant JP (1975) Nervous system neoplasms and primary malignancies of other sites The unique association between meningiomas and breast cancer. Neurology 25(8):705-705

5. Smith FP, Slavik M, Macdonald JS (1978) Association of breast cancer with meningioma. Report of two cases and review of the literature. Cancer 42(4):1992-1994

6. Malmer B, Tavelin B, Henriksson R, Grönberg H (2000) Primary brain tumours as second primary: a novel association between meningioma and colorectal cancer. Int $\mathrm{J}$ Cancer 85(1):78-81

7. Ahsan H, Neugut AI, Bruce JN (1995) Association of malignant brain tumors and cancers of other sites. J Clin Oncol 13(12):2931-2935

8. Rao G, Giordano SH, Liu J, McCutcheon IE (2009) The association of breast cancer and meningioma in men and women. Neurosurgery 65(3):483-489

9. Custer BS, Koepsell TD, Mueller BA (2002) The association between breast carcinoma and meningioma in women. Cancer 94(6):1626-1635

10. Criscitiello C, Disalvatore D, Santangelo M, Rotmensz N, Bazolli B, Maisonneuve P, Curigliano G (2014) No Link between breast cancer and meningioma: results from a large monoinstitutional retrospective analysis. Cancer Epidemiol Biomark Prevent 23(1):215-217

11. Hsu DW, Efird JT, Hedley-Whyte ET (1997) Progesterone and estrogen receptors in meningiomas: prognostic considerations. $\mathrm{J}$ Neurosurg 86(1):113-120

12. Konstantinidou AE, Korkolopoulou P, Mahera H, Kotsiakis X, Hranioti S, Eftychiadis C, Patsouris E (2003) Hormone receptors in non-malignant meningiomas correlate with apoptosis, cell proliferation and recurrence-free survival. Histopathology 43(3):280-290

13. Kirsch M, Zhu JJ, Black PM (1997) Analysis of the BRCA1 and BRCA2 genes in sporadic meningiomas. Genes Chromosom Cancer 20(1):53-59

14. Laugé A, Lefebvre C, Laurent-Puig P, Caux V, Gad S, Eng C, Stoppa-Lyonnet D (1999) No evidence for germline PTEN mutations in families with breast and brain tumours. Int $\mathrm{J}$ Cancer 84(3):216-219

15. Bethke L, Murray A, Webb E, Schoemaker M, Muir K, McKinney P, Lönn S (2008) Comprehensive analysis of DNA repair gene variants and risk of meningioma. J Natl Cancer Inst 100(4):270-276

16. Malmer BS, Feychting M, Lönn S, Lindström S, Grönberg H, Ahlbom A, Kiuru A (2007) Genetic variation in p53 and ATM haplotypes and risk of glioma and meningioma. J Neurooncol 82(3):229-237

17. Bussels B, Maes A, Flamen P, Lambin P, Erven K, Hermans R, Van den Bogaert W (2004) Dose-response relationships within the parotid gland after radiotherapy for head and neck cancer. Radiother oncol 73(3):297-306

18. Wiemels J, Wrensch M, Claus EB (2010) Epidemiology and etiology of meningioma. J Neurooncol 99(3):307-314

19. Milano MT, Grossman CE (2017) Meningioma in breast cancer patients: population-based analysis of clinicopathologic characteristics. Am J Clin Oncol 40(1):11-16

20. Dimitrakopoulos F. I. D., Kottorou A, Antonacopoulou AG, Makatsoris T, Kalofonos HP (2015) Early-stage breast cancer in 
the elderly: confronting an old clinical problem. J Breast Cancer 18(3):207-217

21. Cain SA, Smoll NR, Van Heerden J, Tsui A, Drummond KJ (2015) Atypical and malignant meningiomas: Considerations for treatment and efficacy of radiotherapy. J Clin Neurosci 22(11):1742-1748

22. Hefti MM, Hu R, Knoblauch NW, Collins LC, Haibe-Kains B, Tamimi RM, Beck AH (2013) Estrogen receptor negative/progesterone receptor positive breast cancer is not a reproducible subtype. Breast Cancer Res 15(4):1

23. Harz C, Ludwig N, Lang S, Werner TV, Galata V, Backes C, Rettig J (2014) Secretion and immunogenicity of the meningioma-associated antigen TXNDC16. J Immunol 193(6):3146-3154

24. Grann VR, Troxel AB, Zojwalla NJ, Jacobson JS, Hershman D, Neugut AI (2005) Hormone receptor status and survival in a population-based cohort of patients with breast carcinoma. Cancer 103(11):2241-2251

25. Tantawy HI, Mohamad FF, Ismael AM (2010) The role of advanced MRI techniques in differentiating typical, from atypical and malignant meningiomas. Egypt J Radiol Nucl Med 41(3):411-419 